\title{
Findings of Florid Cemento-Osseous Dysplasia: a Report of Three Cases
}

\author{
Taha Emre Köse ${ }^{1}$, Onur Dincer Köse ${ }^{2}$, Hulya Cakir Karabas ${ }^{1}$, Tamer Lutfi Erdem ${ }^{1}$, İlknur Özcan ${ }^{1}$ \\ ${ }^{1}$ Department of Oral and Maxillofacial Radiology, Faculty of Dentistry, Istanbul University, Istanbul, Turkey. \\ ${ }^{2}$ Department of Oral and Maxillofacial Surgery, Faculty of Dentistry, Istanbul University, Istanbul, Turkey.
}

\author{
Corresponding Author: \\ Taha Emre Köse \\ Department of Oral and Maxillofacial Radiology \\ Faculty of Dentistry, Istanbul University \\ 34093, Capa/Fatih, Istanbul \\ Turkey \\ Phone +90 5554798072 \\ Fax +90 2126214244 \\ E-mail: tahaemre@gmail.com
}

\begin{abstract}
Background: Florid cemento-osseous dysplasia (FCOD) is a benign jaw lesion originating from periodontal ligament tissues usually asymptomatic and diagnosed accidentally at routine dental radiographic examination. The purpose of this paper is to report three cases diagnosed as FCOD with their clinical, radiographic and histological findings.

Methods: Radiologic and clinical symptoms of three cases diagnosed as FCOD are presented. Serum alkaline phosphatase test and biopsy taken from two of the patients are discussed to eliminate the Paget's disease.

Results: Three patients diagnosed as FCOD and called for routine follow-up. Because of no sign of infection or osteomyelitis, conservative treatment was applied.

Conclusions: Radiographic examination is significant for the diagnosis of florid cemento-osseous dysplasia, especially in the asymptomatic cases. The roles of the dentist are to ensure the follow-up of the diagnosed patients and to take the necessary measures for preventing from the infections.
\end{abstract}

Keywords: florid cemento-osseous dysplasia; panoramic radiography; bone diseases.

\author{
Accepted for publication: 29 December 2013 \\ To cite this article: \\ Köse TE, Köse OD, Karabas HC, Erdem TL, Özcan İ. Findings of Florid Cemento-Osseous Dysplasia: a Report of \\ Three Cases. \\ J Oral Maxillofac Res 2013;4(4):e4 \\ URL: http://www.ejomr.org/JOMR/archives/2013/4/e4/v4n4e4ht.pdf \\ doi: $10.5037 /$ jomr.2013.4404
}




\section{INTRODUCTION}

Florid cemento-osseous dysplasia (FCOD) is one of the subgroups of cemento-osseous dysplasia (COD) which was first described by Melrose [1], Abrams and Mills in 1976 [2]. FCOD was also reported as multiple cementoossifying fibroma, sclerosing osteomyelitis, sclerosing osteitis, multiple osteomas, periapical cementoblastoma, Paget's disease of the mandible, multiple enostosis, gigantiform cementoma, florid osseous dysplasia [1, 3$]$. The exact etiology of FCOD is still unknown [2]. Most authorities suggest that pathogenesis of these lesions come from periodontal ligament, because they are seen close to it and have similar histopathology $[\underline{4}, \underline{5}]$. Therefore, few authors believe that remains of cementum in bone after extraction might be a reason of FCOD $[\underline{6}, 7]$.

FCOD affects mostly middle aged to older black women. Male:female ratio reported as 1:2,6 [ㄴ,5]. FCOD is usually asymptomatic and diagnosed accidentally at routine dental radiographic examination. Dull pain, drainage, exposure of the lesion in oral cavity, focal expansion and facial deformities are present when infection occurs $[\underline{3}, \underline{8}]$.

Radiographic image of FCOD is lobular radiopacities that grow with the maturation of lesion surrounded with radiolucent area and located mostly in mandibular premolar-molar region [2,9]. This image is named "cotton wool" appearance and is also seen in Paget's disease of bone [9].

The purpose of this paper is to report three cases diagnosed as cemento-osseous dysplasia with their clinical, radiographic and histological findings.

\section{CASE DESCRIPTION AND RESULTS Case 1}

25 year-old Caucasian woman was referred to a dentist, because of periodontal complaints. Bilateral radiopaque lesions were revealed by dental radiographic examination and consequently, the patient, without any related clinical complaint, was directed to Istanbul University, Faculty of Dentistry.

Panoramic radiograph showed ovoid radiopaque masses in wide radiolucent spaces in the periapical areas of all the molars in both quadrants of the mandible and in the maxillary right quadrant.
The lesion, which located at the apex of \#27 showed no internal calcification (Figure 1). There was no expansion of jaws. Electric pulp tests were applied to the involved teeth: teeth were vital except right mandibular first molar at which a big composite restoration and a poor root canal therapy was observed. It was recommended to patient that retreat her \#46 tooth's root canal therapy in order to prevent a possible infection. The result of the requested serum alkaline phosphatase (ALP) test was $88 \mathrm{IU} / \mathrm{L}(\mathrm{N}: 25-94 \mathrm{IU} / \mathrm{L})$. We diagnosed present pathology as FCOD lesion and decided to follow the patient without taking biopsy. For the patient, who did not have any clinical complaints, radiographic control was recommended twice a year.

Patient's follow-up radiograph, which was taken 6 months later, showed the same condition with the previous one (Figure 2).

\section{Case 2}

71 year-old Caucasian female patient applied to Istanbul University, Faculty of Dentistry, because of the pain in posterior region of the left mandible

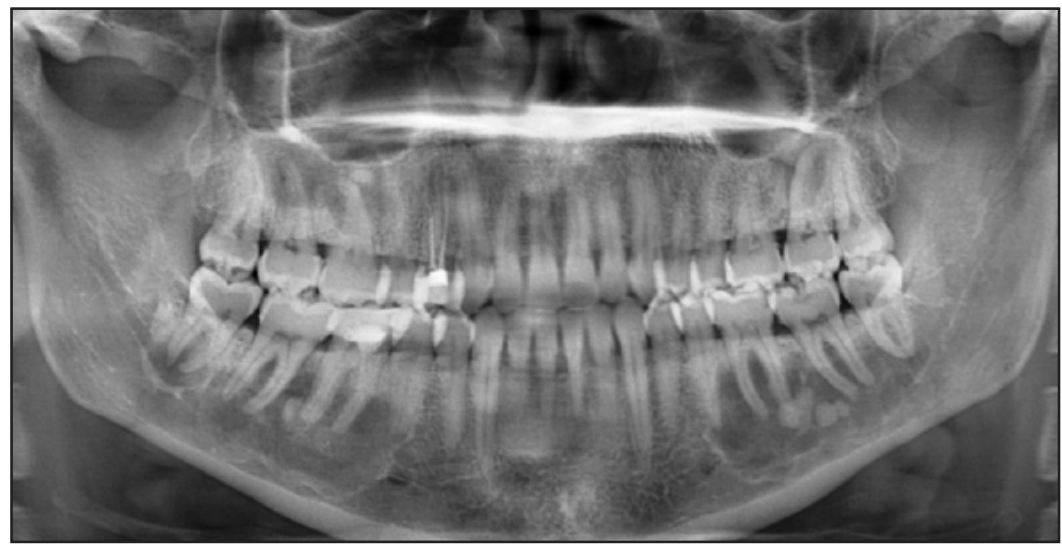

Figure 1. Panoramic radiograph of the patient shows radiopaque masses inside wide radiolucent areas at right maxillary and right and left mandibular molar areas. A radiolucent area is present around \#27 tooth's roots.

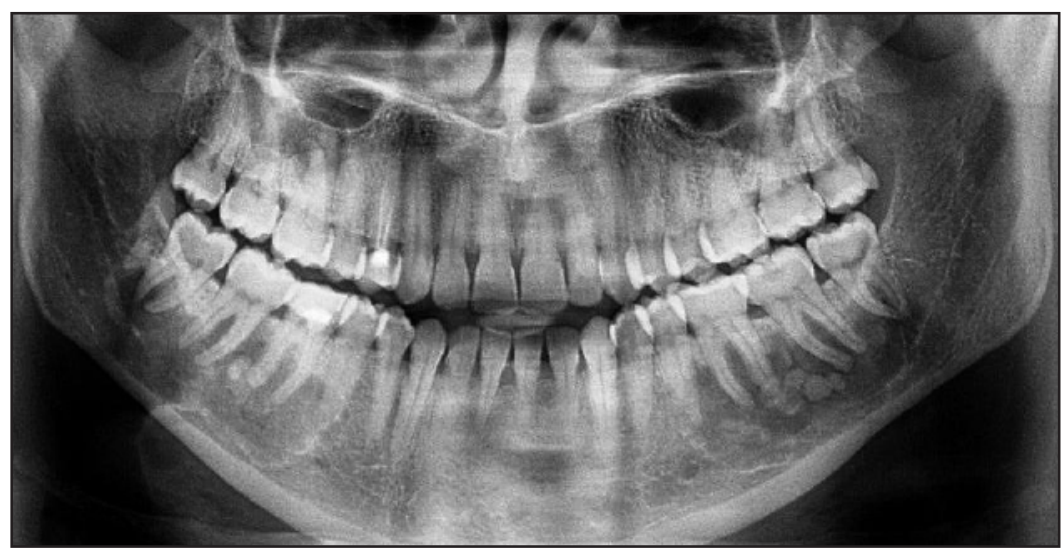

Figure 2. Follow-up radiograph taken 6 months later, no recognizable change is seen. 
when using her total dentures during mastication. She was systemically healthy and had no extraoral symptoms. Intraoral examination showed totally edentulous jaws and normal mucosa. Panoramic radiograph was taken and radiopaque masses were seen at four quadrants, no sign of infection or osteomyelitis (Figure 3). Initial diagnosis was FCOD, but there was no clinical explanation for the pain. Therefore, dental volumetric tomography was taken. In cross sectional images of the dental volumetric tomography a bone spine was detected and we considered that this spine was the reason of pain (Figure 4). Alveoloplasty was performed on left posterior mandible and during the surgical process, the biopsy was performed owing to lesion's close adjacency to surgical area. The result of the histopathological examination was FCOD. No other treatment was thought. The patient was called for follow-up 6 months later.

\section{Case 3}

41 year-old systemically healthy Caucasian female patient was referred to Istanbul University, Faculty of Dentistry, Department of Oral and Maxillofacial Radiology for dental care. Panoramic radiograph obtained due to dental caries and prosthetic indications. Radiopaque ovoid masses were seen at left and right mandibular quadrants (Figure 5). To eliminate the diagnosis of Paget's disease of bone, serum alkaline phosphatase level examination test was performed. Decayed roots of right second molar seen at radiography.

Biopsy was performed at right left molar

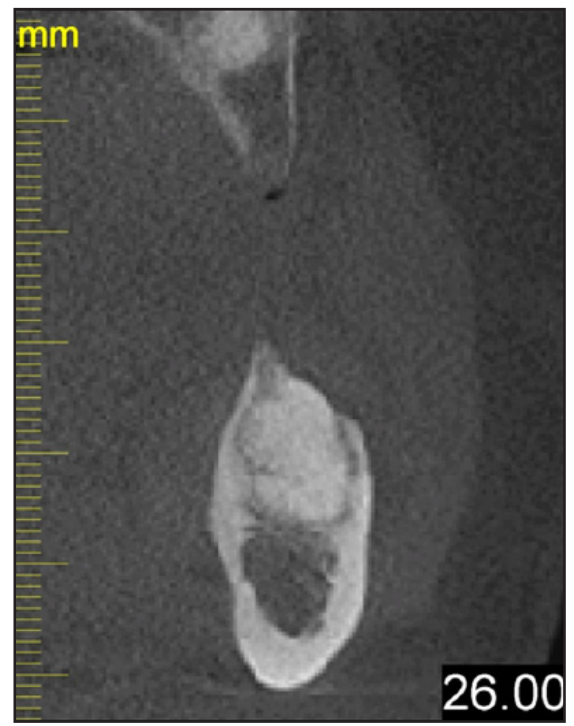

Figure 4. Cross-sectional image showing the FCOD lesion and the spine on the top of the crest. quadrants. region. In histopathological examination, trabecular and compact bone tissue in collagen rich connective tissue stroma was seen. In some area spheroidal hard tissue islands like cementum was detected. Based on the result of the histopathological examination diagnosis the FCOD was established (Figure 6). \#24 and \#47 were extracted and patient was disposed for routine dental treatments.

After 6 months patient was recalled for clinical and radiographic examination. Panoramic radiograph revealed no significant difference (Figure 7).

\section{DISCUSSION}

FCOD classified by World Health Organization in 2005 as bone related lesions and is a non-neoplastic fibro-osseous lesion [2, 5]. FCOD is one of the subgroups of cemento-osseous dysplasia (COD) $[\underline{1}, \underline{2}]$. The other COD lesions are focal cemento-osseous dysplasia and periapical cemento-osseous dysplasia [1]. This classification based on clinical characteristic, location and radiographic features $[2,4]$. These clinical features include lesions' localization and diffuseness.

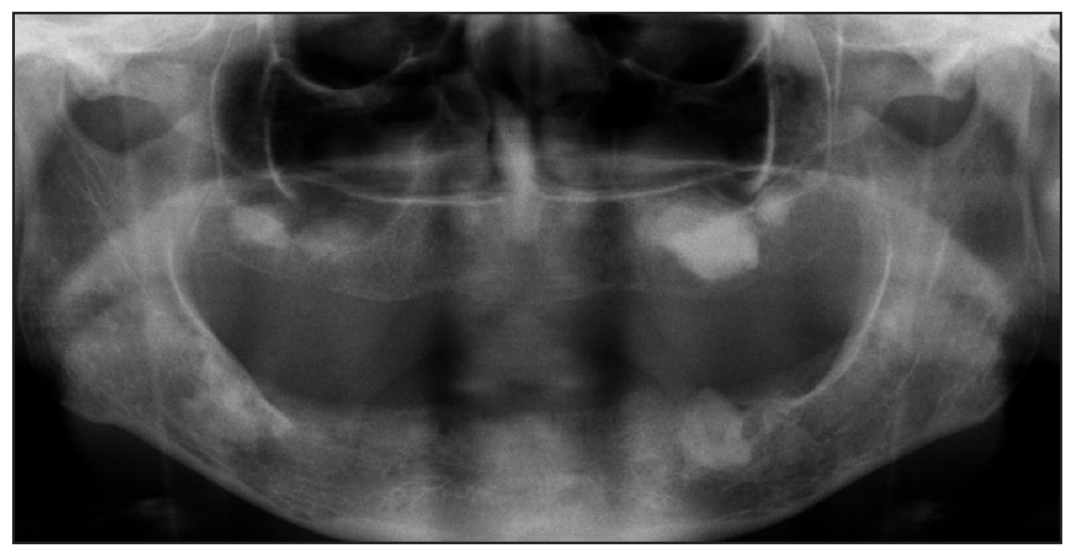

Figure 3. Panoramic radiograph of the patient shows radiopaque masses at four

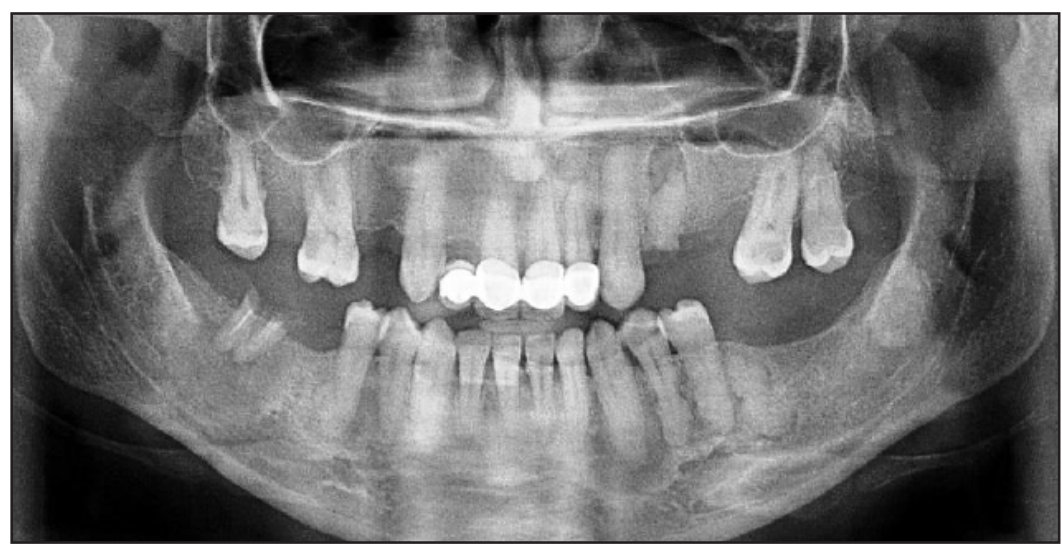

Figure 5. Panoramic radiograph of the patient shows radiopaque masses at both mandibular quadrants. 
Periapical cemental dysplasia usually locates area of apices of anterior teeth and mostly doesn't grow more than $1 \mathrm{~cm}$, focal cemeto-osseous dysplasia usually appears at two or more mandibular anterior teeth or at the apices of molar region, and rarely grow more than $2 \mathrm{~cm}[\underline{5}, \underline{10}]$. FCOD appears bilateral, often quite symmetrical location [ [3]. The density of the lesion has a wide range from radiolucent to almost complete radiopacity [9]. The term "florid" refers to its excessive and widespread location $[\underline{5}, \underline{11}]$.

All types of COD lesions have similar histopathology. In dysplastic period normal bone is replaced with fibrous connective tissue [1]. This fibrous connective tissue contains woven bone, lamellar bone and cementum like particles [4]. As the lesions mature, calcification degree increases [1].

FCOD have three developmental stages and all stages have different radiographic images. First or osteolytic stage is seen as well-defined radiolucent area with loss of lamina dura and periodontal ligament. In the second or cementoblastic stage, small radioopacities appears in radiolucent area, because of deposition of cementum-like droplets in fibrous tissue. Last stage is described as definite radioopacity present in majority of the lesion [10].

Diagnosis is made by clinical and radiographic examination. If the radiological and clinical findings are enough to diagnose, biopsy should be avoided because of infection, sequestrum formation and osteomyelitis risks [2]. Generally, infection risk relies on poor vascularization of the lesion [1]. This condition requires surgical treatment of the lesion. Because of the poor healing, fracture or infection risks, extraction and excision of the lesion are not recommended [2]. For asymptomatic patients the treatment is not necessary and best choice is routine follow-ups and protection from infection $[2,4]$. Treatment options of the symptomatic patients are antibiotic therapy and sequestrectomy [4]. Another possible complication is difficult to control infections due to insufficient antibiotics concentration in the lesion area owing to reduced blood flow [1]. In our cases, there were no infections. Therefore we recommended routine follow-ups and to increase oral hygiene in order to prevent possible infections. Biopsies were taken in case two and three, since the operation areas were adjacent to the lesions.

Differential diagnosis of FCOD must be made with Paget's disease of bone, chronic diffuse osteomyelitis, Gardner's syndrome, familial gigantiform cementoma [ㅁ, 9$]$. FCOD is not seen with skin tumours, dental anomalies

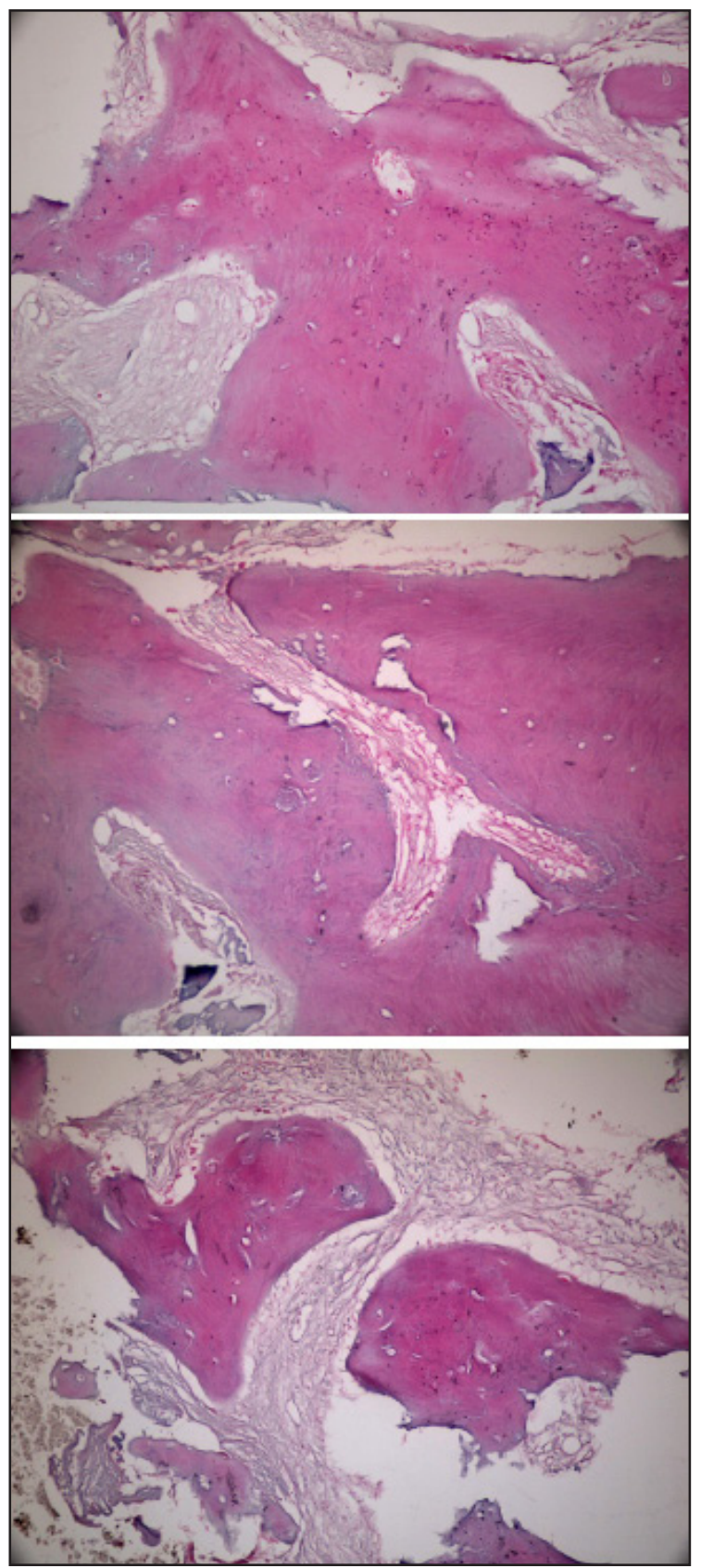

Figure 6. Trabecular and compact bone seen between loose connective tissue (hematoxylin and eosin stain, original magnification $\mathrm{x} 40$ ).

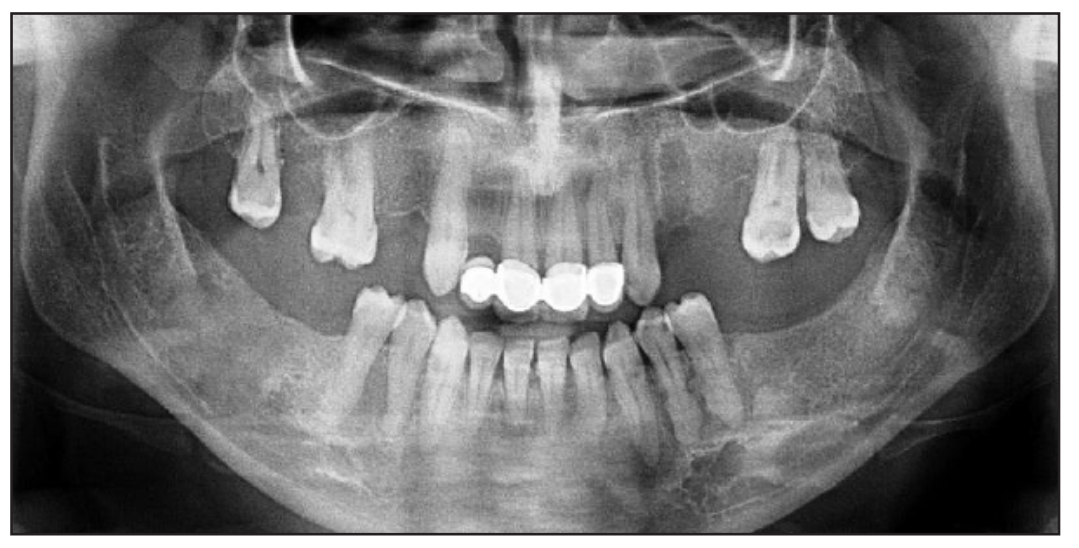

Figure 7. Follow-up radiograph taken 6 months later. 
and skeletal changes like Gardner's Syndrome [3] . In Paget's disease of bone, no radiolucent capsule is present around the radiopaque masses, also it is usually polyostatic and causes raised alkaline phosphatase level $[\underline{3}, 9]$. Chronic diffuse osteomyelitis is not limited in tooth bearing areas and cause unilateral pain and swellings [ $\underline{3}]$.

Familial gigantiform cementoma has familial basis and from this point it is differentiated from FCOD [5]. In our cases, serum alkaline phosphatese levels were in normal ranges and there were no signs of infection. Our cases had neither dental anomalies nor skin tumours and the patients had no familial history.

\section{CONCLUSIONS}

Radiographic examination is significant for the diagnosis of florid cemento-osseous dysplasia, especially in the asymptomatic cases. The roles of the dentist are to ensure the follow-up of the diagnosed patients and to take the necessary measures for preventing from the infections.

\section{ACKNOWLEDGMENTS AND DISCLOSURE STATEMENTS}

There are no relevant conflicts of interest to disclose.

\section{REFERENCES}

1. Gerlach RC, Dixon DR, Goksel T, Castle JT, Henry WA. Case presentation of florid cemento-osseous dysplasia with concomitant cemento-ossifying fibroma discovered during implant explantation. Oral Surg Oral Med Oral Pathol Oral Radiol. 2013 Mar;115(3):e44-52. Epub 2012 Aug 2. [Medline: 22858018] [doi: 10.1016/j.0000.2012.05.020]

2. Sarmento DJ, Monteiro BV, de Medeiros AM, da Silveira EJ. Severe florid cemento-osseous dysplasia: a case report treated conservatively and literature review. Oral Maxillofac Surg. 2013 Mar;17(1):43-6. Epub 2012 Jan 17. [Medline: 22249882] [doi: 10.1007/s10006-012-0314-0]

3. Kim JH, Song BC, Kim SH, Park YS. Clinical, radiographic, and histological findings of florid cemento-osseous dysplasia: a case report. Imaging Sci Dent. 2011 Sep;41(3):139-42. Epub 2011 Sep 15. [Medline: 22010072] [PMC free article: $\underline{3189539]}$ [doi: $10.5624 /$ isd.2011.41.3.139]

4. Neville BW, Damm DD, Allen CM, Bouquot JE. Bone pathology. In: Neville BW, Damm DD, Allen CM, Bouquot JE, editors. Oral and maxillofacial pathology. St. Louis,Missouri: Saunders Elsevier; 2009. p. 641-45.

5. Sanjai K, Kumarswamy J, Kumar VK, Patil A. Florid cemento osseous dysplasia in association with dentigerous cyst. J Oral Maxillofac Pathol. 2010 Jul;14(2):63-8. [Medline: 21731265] [PMC free article: 3125062] [doi: 10.4103/0973-029X.72503]

6. Peter AR, Philipsen HA. Odontogenic tumors and allied lesions. In: Peter AR, Philipsen HA, editors. Florid Cementoosseous Dysplasia. London: Quintessence; 2004. p. 301-9.

7. Paul MS, Roman C. Maxillofacial fibro osseous lesions. Curr Diagn Pathol. 2006 Feb;12(1):1-10. [doi: 10.1016/j.cdip.2005.10.002]

8. Minhas G, Hodge T, Gill DS. Orthodontic treatment and cemento-osseous dysplasia: a case report. J Orthod. 2008 Jun;35(2):90-5. [Medline: 18525072] [doi: 10.1179/146531207225022500]

9. White SC, Pharoah MJ. Oral Radiology: Principles and Interpretation. In: White SC, Pharoah MJ, editors. Diseases of bone manifested in the jaws. St. Louis, Mo, USA: Mosby; 2009. p. 437-40.

10. Bhandari R, Sandhu SV, Bansal H, Behl R, Bhullar RK. Focal cemento-osseous dysplasia masquerading as a residual cyst. Contemp Clin Dent. 2012 Apr;3(Suppl 1):S60-2. [Medline: 22629069] [PMC free article: 3354788] [doi: 10.4103/0976-237X.95107]

11. Rao KA, Shetty SR, Babu SG, Castelino RL. Co-Occurence of Florid Cemento-Osseous Dysplasia and Simple Bone Cyst: a Case Report. J Oral Maxillofac Res 2011;2(3):e5. URL: http://www.ejomr.org/JOMR/archives/2011/3/e5/v2n3e5ht.htm [doi: 10.5037/jomr.2011.2305]

\section{To cite this article:}

Köse TE, Köse OD, Karabas HC, Erdem TL, Özcan İ. Findings of Florid Cemento-Osseous Dysplasia: a Report of Three Cases.

J Oral Maxillofac Res 2013;4(4):e4

URL: http://www.ejomr.org/JOMR/archives/2013/4/e4/v4n4e4ht.pdf

doi: $10.5037 /$ jomr.2013.4404 
Copyright (C) Köse TE, Köse OD, Karabas HC, Erdem TL, Özcan İ. Published in the JOURNAL OF ORAL \& MAXILLOFACIAL RESEARCH (http://www.ejomr.org), 1 January 2014.

This is an open-access article, first published in the JOURNAL OF ORAL \& MAXILLOFACIAL RESEARCH, distributed under the terms of the Creative Commons Attribution-Noncommercial-No Derivative Works 3.0 Unported License, which permits unrestricted non-commercial use, distribution, and reproduction in any medium, provided the original work and is properly cited. The copyright, license information and link to the original publication on (http://www.ejomr.org) must be included. 